\title{
Assessment of stabilization methods for soft soils by admixtures
}

\begin{abstract}
Soil stabilization by admixture was developed in Japan during 1970s and 1980s. The treated soil has greater strength, reduced compressibility and lower hydraulic conductivity than the original soil. The original technique known internationally as the deep mixing method (DMM) was developed simultaneously in Sweden and Japan in the mid-1970s. It is an in-situ soil treatment technology whereby the soil is blended with cementitious and/or other materials. Jet Grouting is suitable to be used as the injection method for the DMM. It utilizes a fluid jet (air, water and/or grout) to erode and mix the in-situ soft or loose soils with grout. The grouting method is one of the ground improvement methods suitable for the soft soil. Chemical stabilization is the effective method to improve the soil properties by mixing additives to soils. Selecting the right method for soil stabilizing however, depends on several conditions like; soil type and layering, magnitude of the load, situation and type of the project, among others. In this paper, the authors have investigated and compared the different methods used according to their characteristics. By utilizing this information and their interrelationship, it is expected that the geotechnical engineers will be in a better position to select a suitable method to improve the soft soils and overcome their difficulties.
\end{abstract}

Keyword: Injection; Jet grouting; Chemical grouting; Deep mixing method; Stabilization 